\title{
CARL GANGOLF KAISER (1837-1895). ARQUITECTO DE LA CORTE DEL EMPERADOR MAXIMILIANO
}

\section{Michael DREWES}

El 8 de abril de 1982 recibí un envío registrado el 27 de marzo de 1982, del maestro, y ahora seguramente doctor, Johann Lubienski, de Graz, Austria, que contenía un legajo fotocopiado de documentos en fojas numeradas del 789 al 829, que se encuentra en el Haus-, Hofund Staatsarchiv, Archivo Doméstico de la Corte y del Estado de Viena, en el cartapacio Maximiliano de México, cartón 16, cuaderno 7, carpeta "m", bajo el título de Kaiser, arquitecto. Dicho cartapacio se refiere a Carl Gangolf Kaiser, nacido en 1837 en Viena, y muerto en 1895 en el manicomio de Inzersdorf cerca de Viena.' Estudió primero en su ciudad natal y luego con Ludwig Lange en Munich, e hizo varios viajes por Europa, América del Norte y Centroamérica. Fue comisionado en 1864 por el emperador Maximiliano como arquitecto de la Corte para trabajos de restauración en los palacios de la ciudad de México y de Chapultepec. Después de la muerte de Maximiliano regresó en 1867 a Viena, donde trabajó pincipalmente para la nobleza; construyó el castillo de Kreuzenstein a partir de 1874, modificó el palacio Auersperg a partir de 1880 y restauró el castillo de Liechtenstein cerca de Mödling, además de haber efectuado obras menores en el palacio Kinsky de Viena, de 1869, y en el castillo de Seebarn, a orillas del Danubio. ${ }^{2}$

Anteriormente, yo ya había escrito acerca de este arquitecto, ${ }^{3}$ mencionándolo simplemente, a falta de mayor información entonces, como C. Kaiser, según su firma en los documentos analizados. Este nuevo legajo que

1 Thieme-Becker, Künstlerlexikon, Tomo XX, p. 45, así como los periódicos Wiener Zeitung, del 3 de septiembre de 1895, Neue freie Presse, del mismo día, y Kunstcbronik, NF VII, 1896, p. 43.

2 Eckart Vancsa. "Zu Carl Gangolf Kayser. Ein Weiner Architekt des Späthistorismus", ARX - Burgen und Scblösser in Bayern, Oesterreich und Sïdtirol. Wien -- St. Michael/ Eppan -München, 1980, pp. 11-17, da una descripción detallada de sus obras en Austria.

${ }^{3}$ Michael Drewes, "Proyectos en el Imperio", en Palacio Nacional, México, Secretarla de Obtas Públicas. Bajo el patrocinio de la Secretaría de Hacienda y Crédito Público, México, 1976, pp. 201-208 y notat5 en p. 319, y del mismo autor, "Proyectos de temodelación del palacio de Chapultepec en la época del emperador Maximiliano", Anales del Instituto de Investigaciones Estéticas, Vol. XIII, Núm. 51, México, 1983. pp. 73.82. Una traducción alemana de ambos artículos, fusionados, apareció como "Projekte Carl Gangolf Kaysers für Kaiser Maximilian von Mexico" en la misma revista $A R X$ de 1980, pp. 3-10. 
contiene cartas, cuentas y convenios, en su mayoría redactadas en alemán, y que se presentan aquí por primera vez traducidos al castellano, vierte nueva luz sobre nuestro arquitecto y lo presenta ahora no en su aspecto de diseñador, sino en los de organizador y administrador de las obras de remodelación no sólo del palacio de Chapultepec, sino también del de Cortés y de la Casa Borda en Cuernavaca.

El primer documento es un convenio que estipula el alcance de los trabajos a efectuarse, firmado al calce por C. Kaiser y el prefecto del alcázar de Chapultepec, Schaffer, a quien erróneamente tuve como otro arquitecto, ${ }^{4}$ resultando ahora que su firma, que aparece en uno de los planos, ${ }^{5}$ es sólo para la aprobación del mismo. La "casa para el señor conde de Biburek", mencionada bajo el inciso 7 , podría ser aquella representada como "casa particular", en mi artículo publicado en los Anales.' A continuación, el texto íntegro del documento: ${ }^{8}$

Convenio con Kaiser

23 de diciembre de 1866

El arquitecto Kaiser se obliga a entregar los siguientes planos dos meses después de su llegada a Europa, en la prefectura del palacio de Miramar: Se obliga a presentar todavía aquí en México los bosquejos a Su Majestad para su dictaminación, en todo caso hasta fines de enero del año entrante de 1867.

Los planos por ejecutarse y sus precios, son:

1. Decoración del palacio en el jardín

2. Gruta

3. Museo

4. Escaleras, terrazas y sus alrededores

5. Pedestal con águila mexicana

6. Iglesia

7. Casa para el señor conde de Biburek

8. El balneario

80 florines
$60 \quad "$
$460 \quad "$
$80 \quad "$
$20 \quad "$
$100 \quad "$
$30 \quad "$
$30 \quad "$

Suma

900 florines

${ }^{4}$ Drewes, en el mismo artículo en los Anales, 1983, p. 79.

5 Plano núm. 89, legajo 1564 de la colección "Orozco y Berra" en la mapoteca del Ob. servatotio de Tacubaya, reproducido en el mismo artículo. (Véase nota ${ }^{4}$ ).

6 Planos núms. 35, 36 y 38, legajo 1564 del Observatorio, ilustrados y mencionados en p. 78 del mismo artículo. (Véase nota ${ }^{4}$ ).

7 Véase nota. ${ }^{3}$

${ }^{8}$ Folio 790 del Legajo del Archivo Domético de la Corte y del Estado de Viena. En lo sucesivo mencionaremos simplemente los folios. 


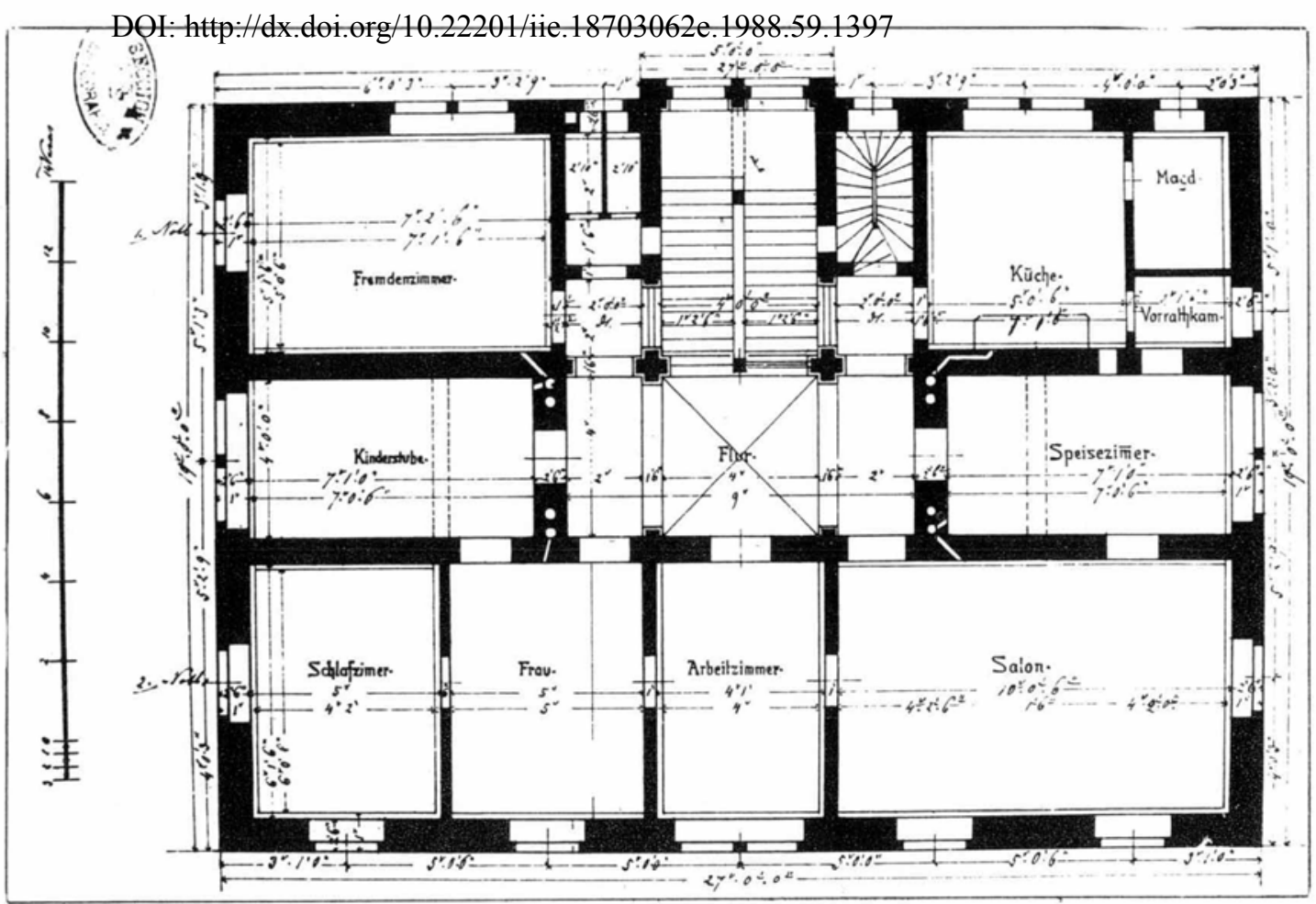

Figura 1. C. G. Kaiser. Planta de una casa particular. Legajo 1564, Colección Orozco y Berra.

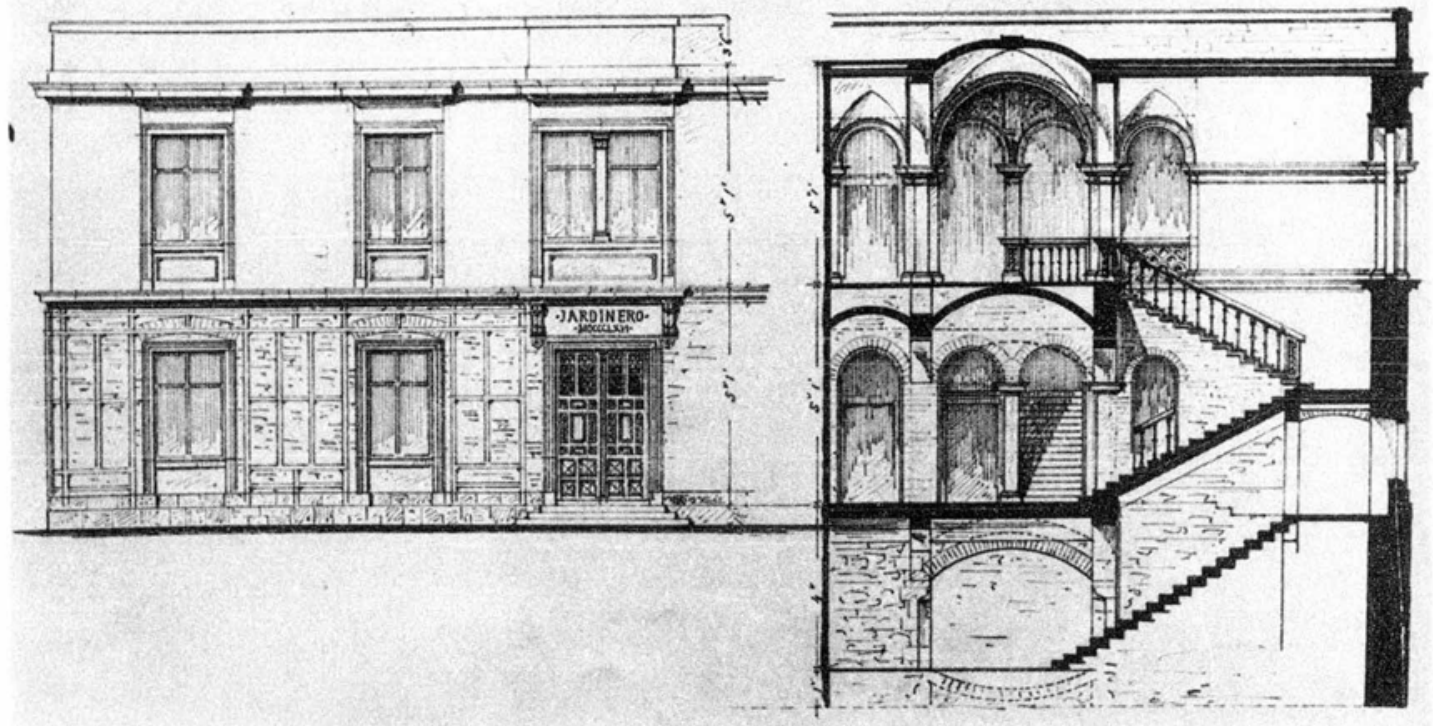

Figura 2. C. G. Kaiser. Fachada y corte de una casa para el jardinero. Legajo 1564. Colección Orozco y Berra. 


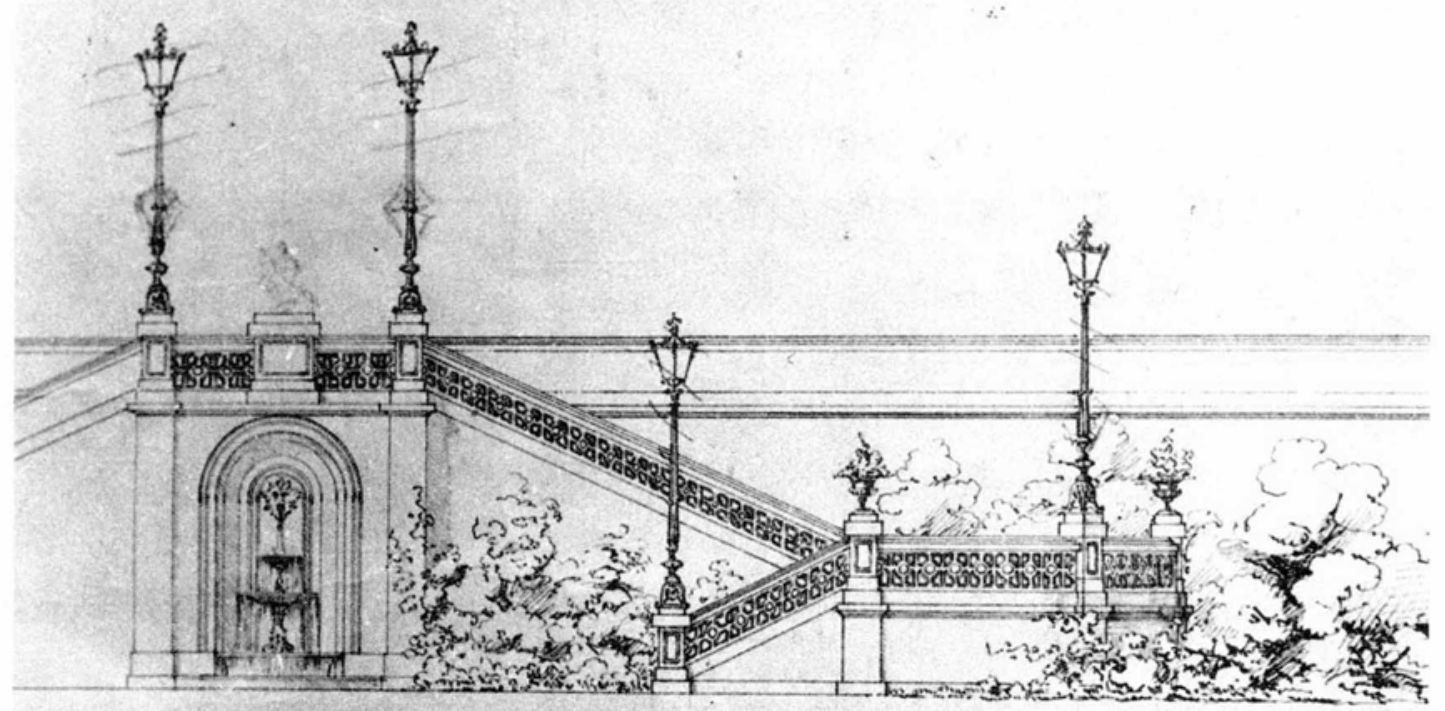

Figura 3. C. G. Kaiser. Diseño de escaleras para el parque de Chapultepec. Legajo 1564. Colección Orozco y Berra. 


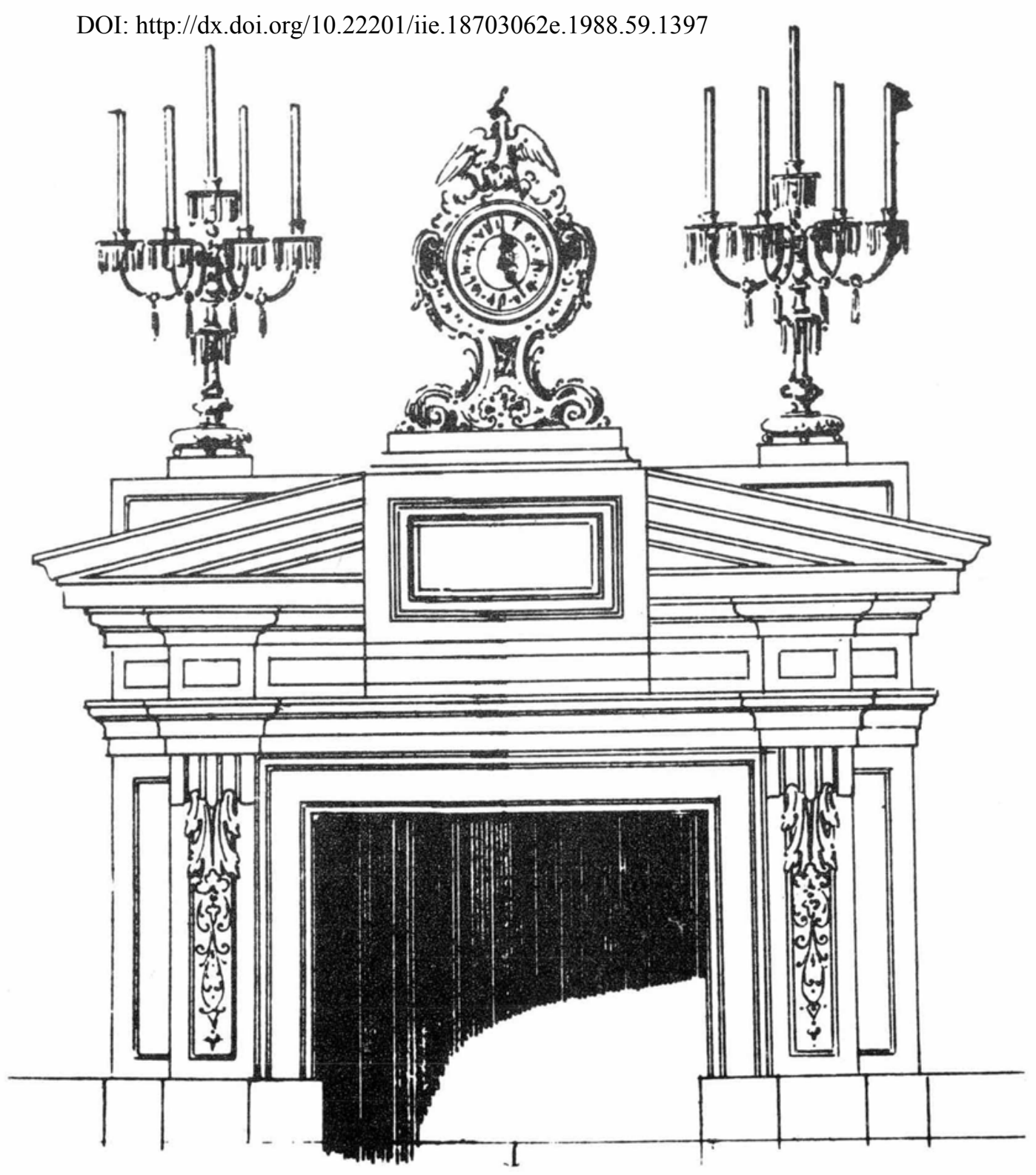

Figura 4. C. G. Kaiser. Diseño de chimenea. Legajo 1564. Colección Orozco y Berra. 


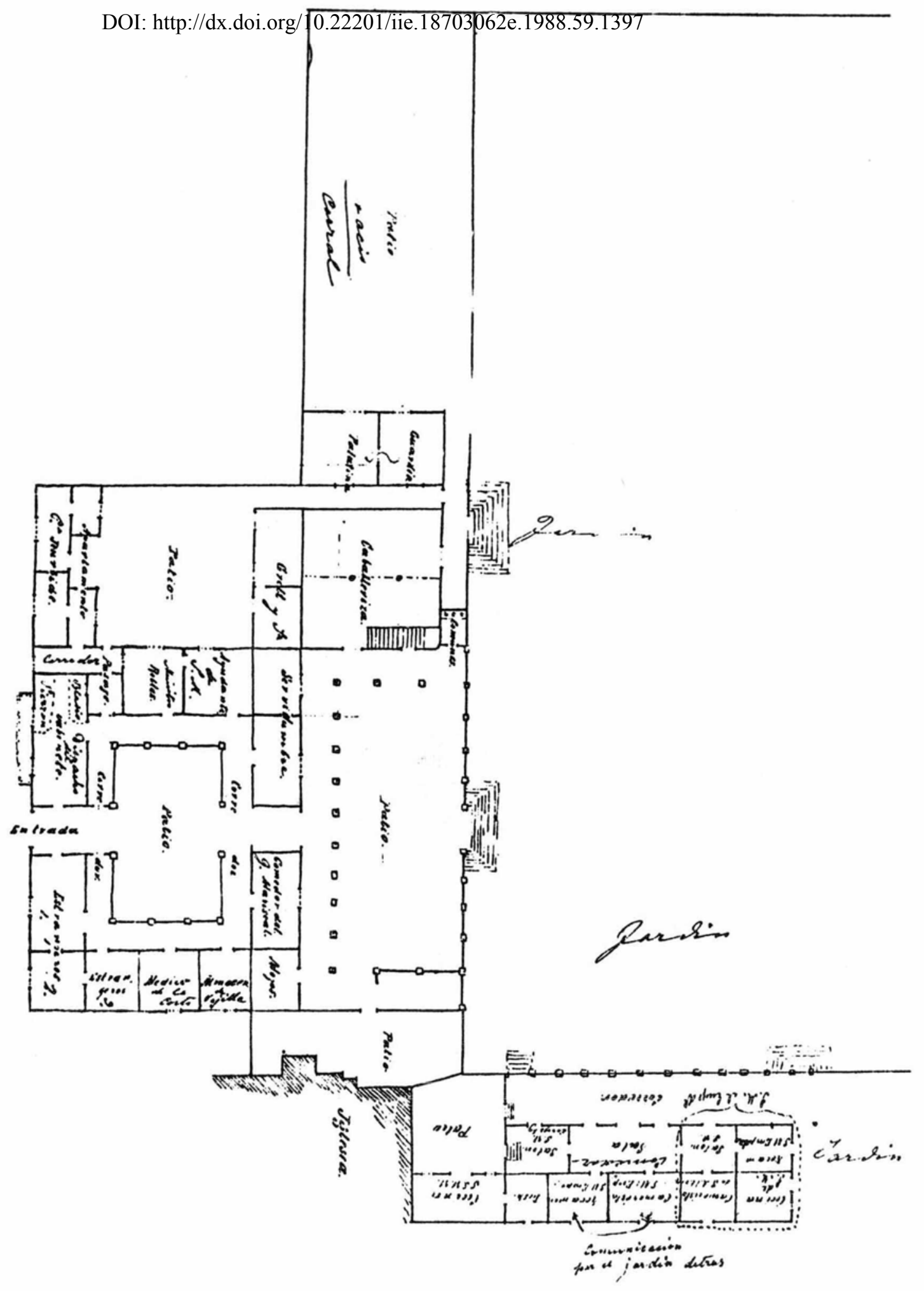

Figura 5. C. G. Kaiser. Arreglo de la Casa Borda en Cuernavaca, para residencia de la Corte de Maximiliano. Folio 794. Colección Orozco y Berra. 
Todos estos planos serán suministrados con todos los detalles necesarios para la obra, y así provistos, se entregarán a la prefectura arriba mencionada.

Para ello el arquitecto Kaiser recibirá en México inmediatamente después de autorizarse los bosquejos, por parte de Su Majestad el emperador la suma de 250 pesas/: doscientos cincuenta:/, y para los planos se habrá de pagar al mismo inmediatamente después de su entrega a la prefectura en Miramar, por esta misma, el precio convenido de 900 florines /: novecientos: / en corriente austriaca, en el banco.

Puebla, a 23 de diciembre de 1866

Por orden de Su Majestad el emperador

$\begin{array}{ll}\text { Kaiser } & \text { Schaffer } \\ \text { Arquitecto } & \text { Prefecto }\end{array}$

Sigue una carta en la cual el arquitecto Kaiser da una breve descripción del palacio de Cortés, manifestando su preferencia por éste a la Casa Borda, para remozarse como habitación del emperador y su Corte: ${ }^{9}$

Su Majestad:

Con la más humilde reverencia me atrevo relataros por la presente acerca del estado del castillo de Cortés:

Que esta casa fortificada era una estancia favorita del conquistador de México se expresa claramente en la disposición de la misma, ya que si bien corresponde a un castillo fortificado de aquellos tiempos, mucho se ha cambiado de manera peculiar para favorecer la vista libre. Así, se hizo necesario un bastión para dominar la pared posterior que presenta dos columnatas superpuestas.

La vieja iglesia, parte del convento perteneciente a ella y la ruina de una casa proveniente de la misma época atestiguan cómo amaba este lugar y cuánto gastaba en él.

En cuanto a la rehabilitación de este interesante edificio, temo, si ha de suceder de acuerdo con su alcurnia, que consumiría mucho tiempo y dinero. Si se trata sólo de hacerlo habitable, lo que sería completamente suficiente, según mi propia opinión, debería sólo emplearse la mediana suma de diez a quince mil pesos, y esto porque no se encuentran aquí ni obreros ni hombres hábiles de negocios.

En cuanto a la selección de los dos lugares entre la Casa Borda y el palacio, me permito observar de la manera más humilde ante Su Majestad que precisamente sólo este último me parece adecuado, ya que la primera tendría que renovarse por completo, y aun así se vería pobre ante la pesada iglesia vecina. Además, la vista podría tenerse por insignificante, comparada con la del palacio.

9 Folio 792 recto y verso, y folio 793. 
Estoy encantado por este hallazgo histórico notable, especialmente porque es una curiosidad arquitectónica que apenas podría encontrarse por segunda vez en México, si el alarife que acompañó al conquistador hubiera pasado más tiempo en su nuevo país, pues debería de haber sido un extraño, ya que lleva exactamente el sello del gusto europeo de aquella época, que debería sobresalir en el continente americano, al menos.

Hoy todavía hice todos los trabajos necesarios para la orientación, y mañana procederé a la toma de medidas y otras cosas.

Espero que Su Majestad me perdone que me haya atrevido a insistir y darme importancia con estas probablemente prematuras observaciones. Esperando más órdenes, lisonjeo mi vanidad en permitirme llamarme, al menos por lo pronto, el humilde servidor de Su Majestad.

$$
\text { C. Kaiser 24-I-66. }
$$

Una carta anónima, ya que le falta el final y el exordio, por lo que no fue posible indagar quién fue su autor, relata las circunstancias relativas a la Casa Borda en cuanto a su adaptación como residencia del emperador. ${ }^{10}$ La acompaña un plano con indicaciones en castellano, de la propia Casa Borda. El texto, traducido, de la misiva es como sigue:

\section{Cuernavaca, a 24 de enero del 66}

A mi llegada a Cuernavaca ayer en la tarde los habitantes todavía estaban en la Casa Borda; además, la servidumbre dispersada en los cuartos pe queños, quienes, sin embargo, tuvieron que salir aun en la noche, para que la casa pudiese disponerse de acuerdo con el plano adjunto.

En la gran sala a la izquierda de la entrada acomodé todo el gabinete, para que los extraños que tengan que tratar con él no corran hacia el patio. La princesa tiene tres cuartos completamente separados, y en el pasillo en el mismo patio vive el señor Grill con su esposa en dos pequeños cuartos, y cerrando hacia atrás hay dos pequeños y sencillos locales para la guardia palatina. El cuarto del ministro Robles es luminoso, seco y está enjalbegado, asímismo el del ayudante.

He asignado un cuarto cerca de la entrada, próximo a la cocina, para la mesa del mariscal, pues Su Majestad no suele fumar, y el séquito desde luego no comerá con las Majestades. Hacia la derecha de la mesa del mariscal, el sofá es la alacena necesaria para la vajilla, etc. y contiguo hay un cuarto para el médico y tres cuartos para los huéspedes.

Su Majestad tiene un salón, una recámara que es primorosa, un cuarto para el ayuda de cámara, y hacia atrás, la cocina separada de Su Majestad. La camarera de Su Majestad [la emperatriz] puede salir hacia atrás por

${ }^{10}$ Folios 796 recto y verso, 797 recto y verso, y 798 . El folio 795 falta, y el 799 es una hoja vacía. El "mariscal" era, desde luego, François Achilles Bazaine, y el "ministro Robles", Luis Robles Pezuela, ministro de Fomento, según el Diario del Imperio del 16 de noviembre de 1865, apud Francisco de Paula de Arrangoiz, México desde 1808 basta 1867, Editotial Porrúa, S. A. Colección "Sepan cuántos ..." Núm. 82, México, 1968 p. 726. 
el jardín con la recámara de Su Majestad [la emperatriz], mientras que el salón de Su Majestad [la emperatriz] está en el frente.

El comedor entre los salones de Sus Majestades, es lo suficientemente grande para veinticuatro personas. El ala destinada a las Majestades está enjalbegada y es muy limpia; las puertas se están haciendo de nuevo y dejan todavía mucho que desear, puesto que Knechtel ha emprendido todo el asunto con poca energía aunque con buena voluntad.

El arquitecto Kaiser ha relinchado (sic) de alegria ante la vista de la Casa de Cortés. Hemos inspeccionado toda la mansión el mismo día de la llegada, $y$ en el frente posterior hacia las rocas hemos descubierto cuatro maravillosos arcos cegados, ante lo cual Kaiser se sorrojó, pues aquella fachada es completamente irregular, con ocho arcos; asímismo el lado hacia el corral tiene dos columnas condenadas, cuyos capiteles son visibles. Kaiser no tuyo descanso durante toda la noche, y al amanecer había ya hecho cantidad de dibujos para la restauración futura y comenzó con el levantamiento de la casa.

La compra de los terrenos hacia el Este, donde está el carnicero, ofrece pocas dificultades, ya que pertenecen en gran parte al ayuntamiento, y el alcalde ha convocado hoy al cabildo para deliberar acerca de la cesión contra una indemnización según el valor catastral estimado. También están en camino pláticas con respecto a los demás terrenos, que no hay que precipitarlas para no asustar a la gente.

Las actuales cabezas de las autoridades son muy útiles, ya que el secretario Archivala añora ser prefecto. Si hasta pronto no se nombra a nadie, uno puede barrer (sic) con él, puesto que la esperanza lo incita a la acción. El alcalde se desvive por Guadalupe; eso se le ve en la punta de sus narices, y si dejamos a los dos empujándose tan apresuradamente, se podría lograr mucho que de otra manera sería imposible.

La parte superior de la Casa de Cortés, donde están los cuartos mejor conservados, se vaciará por completo el 26 de enero. La parte inferior, donde están las mazmorras, no puede evacuarse sino hasta mediados de febrero, ya que hasta entonces se habrá terminado la nueva cárcel.

Mañana se formará una comisión para evaluar la Casa de Cortés, donde Kaiser fungirá como único arquitecto. Aproximadamente se valúa todo junto en cinco mil pesos, el terreno a tres reales la vara cuadrada, como se acostumbra aquí.

En cuanto a la compra de la Casa Borda, hay que ser muy cautelosos, dado que los acreedores tratan de obtener el precio más alto posible, mientras que hasta hace poco uno podía tenerla por diez mil pesos. En la venta judicial del 59 la casa costó cuatro mil, y el jardín, tres mil pesos - este informe me lo dio Archivala quien hasta ahora ha solicitado un acuerdo con los acreedores, sin que se diga que Su Majestad quiere dejarlo.

De esta descripción y del plano adjunto" se colige que en la Casa Borda el comedor afectaba la misma disposición como en el palacio de Chapulte-

$"$ Folio 794 
pec, entre las habitaciones del emperador y las de la emperatriz, tal y como lo relata José Luis Blasio en Maximiliano íntimo. ${ }^{2}$ En el plano se nota además, precisamente, un lugar asignado al propio Blasio, en el "Despacho del gabinete", a la izquierda del zaguán. Por lo demás, se aprecia la separación funcional entre la "zona de trabajo" de la Corte alrededor del acceso y la residencia del emperador y de la emperatriz, adosada a la iglesia.

En esta carta nos familiarizamos también un poco con el entusiasmo de Kaiser por el palacio de Cortés y las intrigas para adquirirlo junto con sus terrenos circunvecinos, y con los pleitos para comprar la Casa Borda, que al parecer se tenía rentada por este momento para alojar a la Corte de Maximiliano.

Sigue el oficio No. 482, fechado en México a 15 de mayo de 1866, en el cual Kaiser expone, largo y tendido, al emperador un método de organización y dirección de las obras que se pensaban llevar a cabo, con el fin de reducir an mínimo la ineficiencia, y con ello, los engaños y las pérdidas materiales. ${ }^{33} \mathrm{El}$ texto habla por sí mismo, y aquí lo presento en su traducción al castellano:

\section{DIRECCION DEL GRAN CHAMBELANATO 482}

Su majestad:

La extraordinaria y generosa condescendencia, con la cual Su Majestad honró de la manera más amable a los hombres de ciencia y de las artes, me anima - aun cuando todavía discípulo insignificante de las mismasrogar a Su Majestad me diese el permiso de presentar ante su Majestad este corto escrito que por una parte expone una reforma a la organización actual de las obras, y por otra, la responsabilidad de mi actual proceder en el asunto.

Después de mi llegada a México, mi primer esfuerzo era conocer las peculiaridades de la manera de construir de aquí, en cuanto a estilo y organización práctica, para cuyo objeto observé como huésped extraño el palacio de México, el de Chapultepec y obras privadas.

Ya durante el viaje había sopesado el orden y la secuencia de la obra asignada de la manera más magnánima por Su Majestad -pero me enteré para mi más profunda vergüienza que no había sido elegido para este honor.

12 José Luis Blasio, Maximiliano intimo. El emperador Maximiliano y su Corte. Memorias de un secretario particular. Bouret, Paris-México, 1905, citado en Alfonso Teja Zabre, Cbapultepec. Guía bistórica y descriptiva, con un plano pictórico del bosque. $\mathrm{Pu}$. blicaciones de la Secretaría de Hacienda y Crédito Público, México, 1938, pp. 126.127. Véase mi artículo en los Anales, 1983, pp. 74-75.

${ }^{13}$ Folios del 800 recto al 802 recto. 
E1 escrito oficial de Su Majestad se traspapeló y se me olvidó hasta que Su Majestad tuviera la merced de recordarse de mí y de mandar llamarme; los señores contratados en el ínterin continuaron llevando los negocios de manera usual hasta que terminaron.

Como ahora las obras han sido detenidas, llegó un momento de transición favorable para instituir en el futuro una dirección de obras reglamentada, y por tanto, me permito presentar de la manera más humilde ante Su Majestad los puntos principales de la misma.

Con el objeto de implementar tales reglamentos constructivos, se compilaron en la vieja Europa del modo tradicional y más ampuloso volúmenes enteros por consejeros de obra superiores, inferiores e intermedios, los cuales de la misma manera comenzaron sus actividades e inventaron bibliotecas enteras de reglamentos, ordenanzas y desórdenes, leyes y privilegios, etc.

Como extracto de las mejores ideas existe en todos los países, fundado en la experiencia y la opinión pública, un método de dirección de obras para el uso municipal y particular, el cual, con algunas modificaciones, estimo lo más adecuado para el uso privado de Su Majestad.

Dado que Su Majestad ha tomado la arquitectura bajo su muy superior protección $\mathrm{y}$ es amigo de ella, es urgentemente necesario posibilitar para Su Majestad un control central de la dirección de las obras, de fácil movilidad para todos los diferentes proyectos, para que puedan evitarse pérdidas innecesarias de tiempo y confunsiones, por lo cual debe estar presente una contabilidad exacta de la dirección de obra y de todos los eventos para su continua inspección, además de los planos originales, listas y registros.

Hasta ahora los trabajos se emprendieron de una manera muy inconexa, sin ninguna relación lógica, de modo que un proyecto obstaculizaba a otro o causaba una cantidad de modificaciones en otros proyectos ya existentes, a falta de una relación preliminar necesaria de la ejecución. Los trabajos se comenzaron sin previsión ni cálculo aproximativo, y por tanto, los precios se dejaban a la merced de los contratistas; si eran demasiado altos, fueron protestados y surgieron litigios, pleitos y escándalos por doquier.

Sucedieron otros casos: Los contratistas que fueron interrumpidos en la ejecución de sus trabajos a precio alzado pedían por un cuarto de su obrā comenzada cuatro quintos de los precios completos, aduciendo que ya habían hecho compras de materiales y preparaciones de todo el trabajo, que tendrian que restituírseles; asi, los precios inicialmente convenidos subieron casi al doble.

En cada cambio de director de obra, así como de arquitectos, se retiraron los planos, las medidas y el equipo de oficina, todo pagado con el monto de la obra, adernás de la pérdida de escritos necesarios para supervisión y control, $\mathrm{y}$ se extraviaron los más urgentes auxilios de construcción, $\mathrm{y}$ tuvieron que restituirse con gastos mucho mayores que al inicio de las obras. Después de haberse trabajado durante casi dos años con una docena de directores de obra, a saber, los señores Hoffman, Hidalgo, con 1200 al mes, $\mathrm{Manero}_{3}$ con 1000 al mes, Rodríguez, con 800 al mes más unos 2000 pesos 
mensuales de gastos de oficina, Méndez, con 250 al mes, con cuatro obreros auxiliares bajo el señor Rodríguez, y un sobrino del coronel Pradillo, no existe ni siquiera la base alrededor de la cual deberían disponerse todos los eventos y trabajos posteriores de manera correcta, y ello es:

El programa de obra, el cual, en la adaptación de un edificio antiguo ya existente debe de seguir con cualquier posible sutileza al mismo. P'or tanto, ante todo: plantas, fachadas y cortes, generales, con listas de los locales caracterizados, listas de todos los muebles, equipos y materiales de construcción, documentos archivados relativos a la obra, los cuales se entregarán o se redactarán en el despacho de la obra para luego modelar el programa, dirigir el posterior inicio de la obra y contabilizar y controlarlo todo.

Le sigue a la redacción detallada del programa para la modificación, cambios y conservación de partes antiguas, las cuales se conformarán básicamente con las peculiaridades de lo existente, la concesión nueva, con todos sus planos y cálculos, $y$ en dado caso, confirmada por la memoria descriptiva necesaria.

Presentación ante Su Majestad.

Autorización, con todas las modificaciones necesarias.

Adquisición de lo aceptado para la ejecución.

Contabilidad:

Orden de $S u$ Majestad

\begin{tabular}{c|l|l|l|l|} 
Pos. No. Fecha $\mid$ Asunto y dónde & $\begin{array}{c}\text { Diseño } \\
\text { No. Fecha }\end{array}$ & Presentación & Aceptación Modificación \\
\hline & & \\
\hline
\end{tabular}

Como no se puede evitar el fraude en su totalidad, por más exacto que sea el control, ya que el director de obra y sus subordinados pueden celebrar convenios entre ellos, depende de la selección de la dirección superior para contrarrestarlo más o menos, pero la finalidad mayor de la contabilidad es la siguiente:

1.- -Todo lo anotado en el libro de contabilidad es palabra juramentada.

2.-Sólo mediante una contabilidad reglamentada son posibles en cualquier momento control, inspección y supervisión de todos los proyectos, para el propio director de obra, así como para el cliente. 
Adquisición

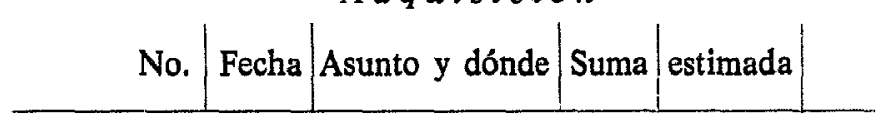

Contabilidad de los proyectos en construcción. A la adjudicación pública al concursante mejor y más barato sigue la licitación, para cuyo objeto se agregará una lista en hojas sueltas al libro de cuentas, utilizándose comúnmente las últimas páginas de él. Entonces, los planos se exhibirăn en los días u horas señaladas en la licitación ante la vista de los hombres de negocios.

Planos, medidas y medios comunes, así como todos los requisitos generales y específicos de construcción relativos a la ejecución y entrega, contratos, indicación de plazos de pago y, en su caso, gastos directos, al no observarse las cláusulas.

Así el joven y fogoso Kaiser, entonces, en 1866, un arquitecto de veintinueve años de edad, trata de dar al emperador -éste, apenas unos cinco mayor que él- lecciones en la materia que se conoce hoy en día como "organización de obras" en las escuelas de arquitectura. Por lo visto, la Corte no tenía la más mínima idea acerca de cómo manejar sus programas de construcción. Nuestro arquitecto señala todos los defectos de la mala, si no inepta administración del Imperio en cuanto a sus obras públicas, como malversación de fondos, fraude, duplicidades innecesarias, corrupción y otros males. A veces, durante párrafos enteros, Kaiser recurre a la simple enunciación de conceptos en vez de redactar un texto fluido, y para contrarrestar las fallas descubiertas, trata de aplicar los criterios anteriormente esbozados a los edificios del "palacio de México", por el cual se ha de entender el Palacio Nacional, para el cual de hecho existen proyectos de remodelación del propio Kaiser, ${ }^{14}$ y el alcázar de Chapultepec, como veremos a continuación..$^{15}$ No sabemos si con "Rodríguez", Kaiser se refería al arquitecto mexicano Ramón Rodríguez Arrangoiti, a quien tocara ejecutar la mayor parte de las remodelaciones en el palacio de Chapultepec. ${ }^{16}$ Sigue, pues, el texto:

${ }^{14}$ Colección "Orozco y Berra", legajo No. 1565, publicado en Palacio Nacional, México, 1976. (Véase nota. ${ }^{3}$ ) El doctor Johann Lubienski escribió su tesis acerca de constitución, administración y ministerios del Imperio. Sería interesante saber a qué conclusiones ha llegado. Arrangoiz critica acremente la catastrófiça y desatinada administración de Maximiliano, en su obra, pp. 590, 736-741. (Véase nota. ${ }^{10}$ )

${ }^{15}$ Folio 802 verso, 804 recto al 805 verso. El folio 803 es una hoja vacía.

16 Véase mi attículo en Anales, 1983, p. 80. 
Para el fácil manejo de las medidas es necesario conocer la representación del proyecto en su construcción, dirigir y deliberar las modificaciones fácilmente y poder conducir a cualquier hora el posible pero ordenado final de los trabajos.

Notas: Recepción del sitio o proyecto de construcción, incluyendo los materiales y equipos, en su caso. En las diferentes obras foráneas existirán los medios necesarios, mientras que en el despacho principal se depositarán todos los documentos relativos, planos de control y los contratos.

Disposición de los trabajos todavía necesarios:

Palacio de México y Chapultepec.

Inventario viejo: plantas, fachadas y cortes.

Inventario de todos los locales existentes, muebles, equipos de construcción, como herramientas, andamios, instrumentos, etc., materiales, documentos y planos.

Entrega de todo aquello al director de obra encomendado con la supervisión y ejecución. Depósito en la oficina central (en Chapultepec, en México, y en la intendencia, entre los diferentes contratistas y arquitectos actualmente dispersados, inaccesibles para los requerimentos prácticos necesarios).

Secuencia de los trabajos por comenzarse o continuarse y programa por implementarse en México y Chapultepec, y de la división usual y final de los conjuntos constructivos, a saber:

1.-Terminación de las habitaciones necesarias en cuanto a acabados, viviendas de huéspedes, oficiales y sirvientes.

2.-Vestíbulo, pasillos, escaleras, salas, etc.

3.--Patios y fachadas.

Obras nuevas en México: trono y terraza

? teatro

? establos, para los carruajes de gala de la Corte

(Puesto que estimo como mucho mejor que en la cercanía del palacio en cuestión se dispongan también los anexos propios para servicios y establos).

Chapultepec: Por terminarse de nuevo y adentro:

$$
\begin{array}{rl}
?=\begin{array}{c}
\text { secuencia por } \\
\text { averiguarse }
\end{array} & \text { ? Pabellón en la glorieta } \\
& 3 \text { Casa del guardia } \\
& - \text { ? Decoración } \\
& - \\
10 & ? \text { Cambio del conducto de agua } \\
&
\end{array}
$$



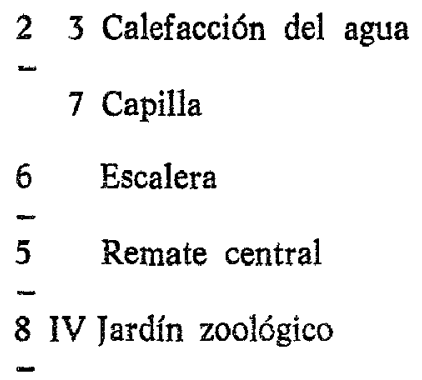

Cuernavaca: Sinopsis general del partido, y fachadas
Averiguación exacta
Jardines y patios, etc.

Listas de precios, por separado, para cada uno de los proyectos, con totales y plazos fijados. Para ésto, el constructor o ejecutor de los trabajos se sujetará al plazo de terminación, y el pago fijado del mismo modo tan exacto se verificará sólo para el trabajo terminado de manera contractualmente correcta. Si el constructor no cumple con el plazo de terminación, se juzgará según la cláusula de castigo estipulada en el contrato de obra. Unicamente por medio de una dirección de obras centralizada, Su Majestad mantiene todos los hilos en sus manos para el conocimiento del estado de obra y su avance, asi como del control para cualesquiera plazos, según la disposición de Su Majestad, y en el caso de cambio de director de obra o de arquitecto, la ejecución futura queda sin obstáculos ni influencias. Así, todos los planos de conjunto, detalles y cálculos, junto con la contabilidad, tienen que estar definidos y listos para toda la obra, a partir de los cuales se encontrarán anotados exactamente en la bitácora de obra todos los contratos, cuentas y recibos según sus plazos de pago correspondientes, de modo que en un cambio del personal de dirección de obra el nuevo supervisor, al hacerse cargo del edificio, sólo tendrá que cerciorarse de su veracidad para poder tomar la responsabilidad por la continuación de la obra.

(Pero es urgentemente necesario para el orden, que sólo una cabeza esté encargada de ejercer la supervisión, modificación, control y ejecución, y que a ésta se confiera todo el poder centralizado sobre el personal de construcción que se encuentre en los diferentes proyectos, para que tenga él el poder del mando único.)

El mismo es entonces el único responsable ante Su Majestad mientras que el personal subordinado lo es ante él, lo que tiene que convenir con el mismo y depositarlo por escrito an la cancillería para que en caso de pleitos, si él lo apela, pueda revisarse y verificarse.

Los leventamientos del palacio de México se hicieron pocas veces (nueve) y no existen por ninguna parte, etc. Por tanto, a partir de ahora, todos los trabajos hechos se habrån de entregar y registrar en la cancillería. La persona en cuestión recibirá una constancia de recibo confirmada con al 
sello de la obra, con número y fecha, para poder encontrar cada pieza inmediatamente.

En todo esto es necesario que una buena oficina obtenga al menos una caja grande para los documentos, unas mesas para dibujar y escribir, así como algunos de los muebles más indispensables.

Que se asegure Su Majestad de que el más humilde suscrito no redactó este escrito por vanidad ni por algún gesto ufano sino que creyó haber tenido que corresponder a sus obligaciones.

El devoto servidor de Su Majestad

C. Kaiser.

Enseguida, Kaiser se repite en una corta misiva dirigida al emperador en los mismos términos, ${ }^{17}$ y agrega un breve resumen, ${ }^{18}$ seguramente con el objeto de martillarle más al cerebro del soberano los principios de una buena organización de las obras públicas del Imperio:

\section{Cuernavaca, a 18-V-66}

Si le gustara a Su Majestad encomendarme a mí los diseños, compilar y ordenar todo el trabajo arquitectónico en ambos palacios, el de México y el de Chapultepec, y atender el castillo de Cuernavaca, entonces, dentro de tres meses, estaré listo para entregar a Su Majestad los siguientes planos constructivos y presupuestos necesarios, siempre y cuando no se me quiten los medios auxiliares indispensables para ello. ([, . . ilegible...] Entrega de los planos viejos, etc.)

Palacio de México I. Todos los planos de conjunto con su completa distribución

II. Fachadas y escalera

Chapultepec

I. Castillo del conjunto superior

II. Casa del guardia

III. Escaleras

IV. Capilla

V. Decoración

Después de la autorización por Su Majestad, ajuste de los presupuestos, averiguación de [...ilegible...] y contratos.

17 Folio 806 recto y verso. Las "fachadas y escalera" del Palacio Nacional, de hecho existen en planos dibujados por Kaiser, en la Colección "Orozco y Berra", legajo 1565, y fueton publicados en la memoria sobre el edificio, de 1976. (Véase nota. ${ }^{3}$ ) Del mistro modo tenemos un plano con planta, cortes y fachadas, de la "capilla" en la misma contribución a la monografía del Palacio' Nacional, y una perspectiva con el título de "Kapelle Chaplt." del propio Kaiser, se refiere a un proyecto para el alcázar de Chapultepec. Se trata del plano No. 37 del legajo 1564 de la Colección "Orozco y Berra", que apareció en el artículo de los Arales, 1983.

18 Folio 807 recto y verso. 
Según el nuevo programa, es decir, entrega de todas las adquisiciones, con planos, presupuestos, cláusulas, dibujos, etc. al comité de la compañía en cuestión, de acuerdo con el contrato, e indicación exacta de todas las estipulaciones, todo el asunto se simplificó mucho. Por tanto aquel comité tiene que seleccionar a sus subordinados y operarios él mismo, y es el único responsable por los trabajos contratados, de acuerdo con calidad y tiempo.

\section{Resumen}

1.-Acabado y terminación de los trabajos comenzados y en proceso de construcción, en un plazo determinado.

2.-Control del estado de obra, completamente detallado, y entrega de todos los planos, según los cuales se construyó, con todos los levantamientos, presupuestos, precios según el material existente, y lista del equipo (herramientas, instrumentos, muebles de oficina, etc.), junto con las cuentas pagadas o por pagar, y toda la contabilidad existente, para poder elaborar y terminar el informe de dirección.

3.-Entretanto se aprovecha el tiempo para la elaboración de los trabajos de acabado que habrán de emprenderse en el futuro de acuerdo con el nuevo sistema, para la terminación total de los trabajos en toda su magnitud, para presentarse a Su Majetsad y personas intermediarias para su revisión, modificaciones necesarias y autorización final, incluyendo planos y medidas.

4.-Después de esto sigue la contratación con la empresa. Para ello se fija exactamente el contrato de acuerdo con los puntos financieros y técnicos, previamente revisado el primero por hombres de las finanzas en cuanto a constitución del préstamo, sus hipotecas y concesiones y amortización final, y el último, por técnicos de la construcción.

5.-La entrega y recepción y ejecución de los proyectos, según una secuencia exactamente establecida, es decir, un proyecto después de otro, en tiempos fijados y con multas convencionales porcentuales al no observarse los plazos.

6.-Entrega de los proyectos terminados a la prefectura del palacio.

Lo que sigue en este legajo del Archivo Doméstico de la Corto y del Estado en Viena, son cuentas de gastos de viaje del propio Kaiser y de su esposa: ${ }^{19}$ el de los costos de la diligencia que el arquitecto debía tomar el 14 de junio de 1866 de Puebla a México, ${ }^{20}$ de la capital a Puebla el 11 de junio del mismo año, ${ }^{21}$ uno de la señora Kaiser, de Paso Macho, Ver., a Puebla, del mismo día. ${ }^{22}$ El oficio No. 78 , redactado en castellano por el ya men-

19 Folios del 808 al 814.

20 Folio 815 recto y verso.

21 Folio 816 recto y verso.

22 Folio 817 recto y verso. 
cionado prefecto Schaffer es importante, ya que en él se confirma el nombramiento de Kaiser como arquitecto de la Corte, se le autorizan los gastos de viaje de su esposa y se le asigna un salario mensual: ${ }^{23}$

\section{Prefectura del Alcazar \\ de Chapultepec \\ No. 78}

Chapultepec, Febrero 11 de /866.

S. M. me encarga manifieste á $\mathrm{V}$. en contestación á la solicitud que le dirigió, que ya dá la órden para que se estienda el nombramiento de Arquitecto de la Corte á favor de $V$. y que se le adelanten mil pesos por cuenta de sus sueldos; también dispone pagar el gasto del viage de su Señora esposa de $V$. hasta esta Capital y la dá permiso para que yaya á encontrarla á Veracruz: por lo que toca al mueblage de la casa, S. M. dispone se le abonen á $\mathrm{V}$. ochocientos pesos anuales por alojamiento, debiendo $\mathrm{V}$. gozar el sueldo de doscientos treinta pesos mensuales.

Lo que digo á $V$. como resultado de su instancia relativa, rogándole me manifieste en contestación si esté ó no conforme con estas condiciones.

\section{E1 Prefecto \\ Schaffer}

A1 Sr. Kaiser, Arquitecto de la Corte.

E1 salario de 230 pesos mensuales asignado a Kaiser fue elevado a 250 pesos en el oficio No. 81 del 19 de febrero de 1866 del mismo Schaffer. ${ }^{24}$ Contamos con una reclamación por gastos todavía no cubiertos a Kaiser por el emperador, relación de costos de viajes a Chapultepec, mensajes y correo, etc. ${ }^{25}$ facturas del Consorcio Austriaco en la 1a. Calle de San Francisco, 13, del 31 de agosto de $1866,{ }^{26}$ del Almacén de Vidrios Planos y Cristales de Francisco Hidde, Callejón el Espiritu Santo No. 1, del 5 de octubre, ${ }^{27}$ y de la Ferretería y Mercería Calle de la Palma No. 5 de Guillermo Lohse y Uhrlaub, del 16 de julio de $1866 .^{28}$

El legajo termina con una lista de personajes de la Corte, entre los cuales el "ministro Esteva" era José Maria Esteva, quien renunció junto con José Fernando Ramírez, de Negocios Extranjeros, Luis Robles Pezuela, de Fomento, y Juan Peza, a su cargo el $\overline{3}$ de marzo de 1866, habiendo sido nombrados todos ellos comisarios imperiales en reconocimiento de sus ser-

\footnotetext{
23 Folio 820.

24 Folio 822.

25 Folio 824.

26 Folio 810.

27 Folio 825

28 Folio 826.
} 
vicios." "Blasio" era, desde luego, José Luis Blasio, el secretario particular de Maximiliano. He aquí la lista: ${ }^{30}$

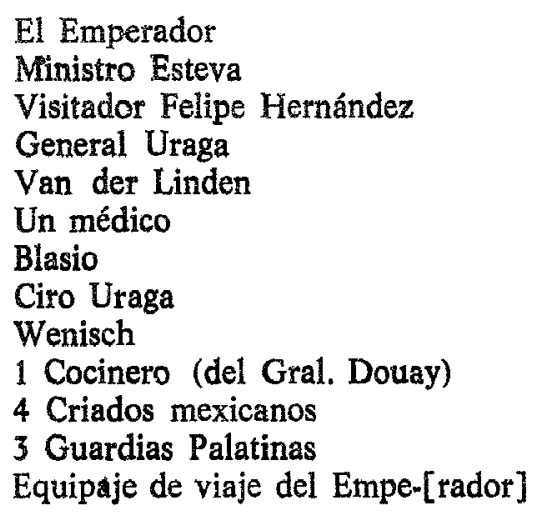

A ésta sigue una hoja inconclusa, con instrucciones para un tal Hoffmann, para arreglar la casa del cabildo en Guadalupe como residencia, probablemente temporal, de Sus Majestades: ${ }^{31}$

Apuntes para Hoffmann

Casa del cabildo = Habitación que debe prepararse en Guadalupe, para SS. MM.

Sala de recepción: Poner las vigas, puertas y ventanas, guardapolyos color de madera con filetes de oro, así como en las otras piezas, en las paredes antigua tapicería roja. Una chimenea entre los dos balcones con un espejo antiguo, un reloj y dos candelabros, un candil de cristal y doce albortantes (sic) de pared, de cristal también. En las paredes algunos cuadros religiosos antiguos con marcos antiguos, alrededor de las paredes bancos de terciopelo rojo (modelo de Puebla). Retrato del Papa recién enviado. Cuadro de la Virgen de Guadalupe que está en el guardamueble de palacio. Alfombra gruesa, de forma antigua.

Los dos tocadores con sus chimeneas en cada uno un tocador, un agua manil, tres sillones tapizados y seis sillas de bejuco.

Sobre las chimeneas espejos, reloj y dos candelabros. Cerca de las chimeneas leña $\mathrm{y}$ utensilios, gruesa [...]

${ }^{29}$ Arrangoiz, op cit., p. 747. El general José López Uraga era "consejero efectivo de antiguo nombramiento", según decreto publicado en el Diario del Imperio del 17 de octubre de 1866, apud Atrangoiz, op. cit., p. 782, y el general Douay participó junto con Bazaine y Forey en el sitio de Puebla en 1863, idem, pp. 533.534.

30 Folio 828. El folio 827 es una hoja vacía.

31 Folio 829 
De Kaiser existe precisamente un diseño ${ }^{32}$ que podría corresponder a la "chimenea entre los dos balcones, con un espejo antiguo, un reloj y dos candelabros", aunque esta carta no es de puño y letra de nuestro arquitecto. El que la escribió, en español, por cierto, pudo haber tomado en cuenta algunas sugerencias del alarife austriaco.

He aqui a un Carl Gangolf Kaiser, acerca de quien en publicaciones an. teriores comenté sus cualidades como arquitecto diseñador y proyectista, presentado ahora como un hábil manipulador que a sus escasos veintinueve años logró granjearse la voluntad de Maximiliano y ser nombrado para una posición importante dentro de la Corte, y todo por haber criticado básicamente los malos manejos en la administración de las obras públicas del Imperio y propuesto reformas y mejoras en este aspecto. Si bien era un arquitecto de muy buen gusto en el diseño y muy capaz de plasmar de manera convincente en el papel sus ideas, sus propuestas de remodelación, tanto del Palacio Nacional como del alcázar de Chapultepec, hubieran desvirtuado considerablemente el carácter de estos edificios. Pero él era obviamente una presa del historicismo ecléctico tardío europeo, y después de la caída del Imperio logró alcanzar en sus obras austriacas mayor sensatez y adaptación a la dignidad de los edificios que restauró, tal vez debido también a su natural proceso de maduración. En México estaba a punto de forzar los neoestilos - no se sabe hasta dónde Kaiser sufriera las influencias de Viollet le Duc (1814-1879) - sobre construcciones netamente coloniales, si sus proyectos se hubieran realizado, mientras que en Austria su actitud era más acorde con el carácter de la arquitectura de ese país.

32 Legajo 1564 de la Colección "Orozco y Berra" ya mencionada. 